Research Article

\title{
Multiobjective Optimization of Sustainable WCO for Biodiesel Supply Chain Network Design
}

\author{
Nana Geng (i) ${ }^{1}$ and Yixiang Sun (D) $^{2}$ \\ ${ }^{1}$ Nanjing University of Posts and Telecommunications, Nanjing 210023, China \\ ${ }^{2}$ Nanjing University of Aeronautics and Astronautics, Nanjing 211106, China \\ Correspondence should be addressed to Yixiang Sun; sunyixiang@nuaa.edu.cn
}

Received 19 December 2020; Revised 18 February 2021; Accepted 26 February 2021; Published 9 March 2021

Academic Editor: Tingsong Wang

Copyright ( 2021 Nana Geng and Yixiang Sun. This is an open access article distributed under the Creative Commons Attribution License, which permits unrestricted use, distribution, and reproduction in any medium, provided the original work is properly cited.

\begin{abstract}
Bioenergy is attracting more attention worldwide due to its environmental and economic benefits. The design of a feasible biodiesel supply chain network can effectively improve the production and use of biodiesel and then further promote the development of the biodiesel industry. As an easy recyclable material with high yield, kitchen waste has a good prospect and can solve public health and safety problems. This paper takes the kitchen waste producing biodiesel as the object to design and optimize the biodiesel supply chain in order to improve the sustainable development of biodiesel industry and the operational efficiency of the biodiesel supply chain. By designing a sustainable biodiesel supply chain model under defined conditions, it proposes strategic and tactical decisions related to location, production, inventory, and distribution within multiple planning cycles. In order to effectively solve the model, a Pareto optimal NSGAII heuristic algorithm is proposed and applied to a practical case study of restaurants in Jiangsu Province. The efficiency of the method and the optimal solution are verified by a case study. The overall optimization of biodiesel supply can effectively improve the efficiency of supply chain, reduce system cost, improve the profit of biodiesel operators, and promote the sustainable development of biodiesel industry, which has important guiding significance and reference value for the practice of biodiesel supply chain network planning.
\end{abstract}

\section{Introduction}

Nowadays, food wasting is becoming a common problem of global resources and environment. Most countries, including the United Kingdom, the European Union, the United States, and some developing countries, face this challenge. In the UK, about $30 \%$ of the food in the market eventually becomes kitchen waste every year, with a total amount of about 6.7 million tons [1]. Figure 1 shows the fluctuation of China's kitchen waste productivity and growth rate during 2009-2019 [2]. With the economic growth and the improvement of residents' consumption level, people's consumption of food and beverage is increasing day by day, which brings about the rapid growth of kitchen waste. According to statistics, the annual output of kitchen waste in China was more than 120 million tons, with an average daily output of $27.4 \mathrm{t} /$ day [3]. Among them, more than 60 million tons of kitchen waste is produced in major cities, especially in the Yangtze River Delta and other cities with developed catering industry [4]. The daily production of kitchen waste reaches more than 2000 tons.

The Chinese government highly supports the development of the biodiesel industry with kitchen waste as the raw material. In the development policy of the biodiesel industry (2015), it clearly states that kitchen waste should become the main raw material of biodiesel, and its supply chain needs effective design to improve the overall operational efficiency. The Chinese government promotes the centralized treatment and resource utilization of typical urban wastes, such as kitchen waste, construction waste, garden waste, and urban sludge. It is planned that the domestic kitchen waste recycling rate will reach $30 \%$ by 2020 . Although the data for 2020 have not yet been released, according to the statistics from previous months, this indicator has almost reached. 


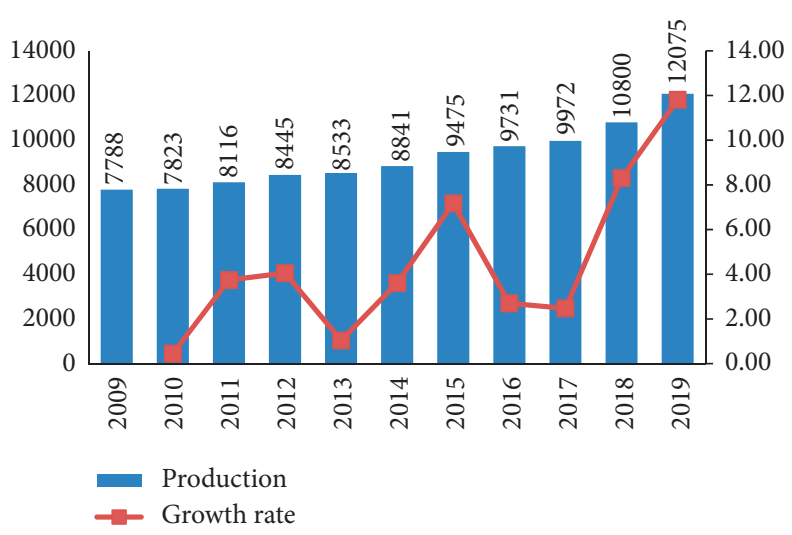

FIGURE 1: 2009-2019 annual production of kitchen waste in China.

Optimal design of the kitchen waste supply chain has great social significance. This paper is to study the modeling, solution, and application of biodiesel supply chain in the determination environment. Firstly, through the in-depth discussion of previous research papers, it is believed that, in the process of modeling, only the integration of effective biodiesel supply chain network system can improve efficiency. Therefore, it is necessary to consider the design of supply chain from the perspective of integration, specifically including the following: study the integration of facilities, propose inventory and distribution strategies, and make decisions on the location, capacity level of pretreatment facilities, and biodiesel refinery facilities in each period. Secondly, considering sustainability, a mixed integer linear programming model is constructed to solve three optimization problems of economic objectives, environmental objectives, and social objectives in the biodiesel supply chain. Thirdly, in terms of research methods, it is difficult to find accurate solutions by branching and delimitation for largescale examples, and the algorithm based on group search mechanism has advantages for solving nondominant solution sets of multiobjective optimization problems. So, NSGAII, an improved multiobjective genetic algorithm, is adopted as the solving algorithm in this paper. Finally, in terms of application and analysis, this paper conducts a case study based on the actual data of Jiangsu Province in order to illustrate the potential use of the model and the decisionmaking solutions in the real environment.

\section{Literature Review}

2.1. Sustainability of Biofuel Supply Chain. Biofuel is known as a renewable alternative to traditional petroleum-based fuels for their low impact on ecosystems. Improving the sustainability performance of biofuel supply chain should be considered as a goal and standard for optimization of the biofuel supply chain. Energy sustainability requires that the needs of managing environment, achieving economic prosperity, and improving quality of life to be met artificially not only the present generation but also the future generations. At present, sustainable supply chain design and optimization has become an emerging method, which tries to take environmental, economic, and social decisions into full consideration [5]. Economic sustainability means the most important objective of the biofuel supply chain is to produce biofuel in an economically viable manner [6]. The research on economic sustainability includes the following contents: the debate between food and energy [7], the balance between efficiency and energy [8], the budget of the biofuel industry [9], the optimization of supply chain operating costs and profits [10], the evaluation of supply chain present value [11], and the avoidance of investment risks [12]. With the improvement of environmental awareness and the tightening of environmental policies, research on environmental sustainability has attracted more and more attention in the past few decades [13]. Early work tends to focus on some environmental aspects of the engineering process, such as waste management and net heat consumption [14]. Now, the study of environmental sustainability pays more attention on how to reduce the land, water, and energy consumption, reduce carbon emissions, and reduce pollutant discharge such as carbon emissions and its environmental impact on the global warming problem [15], the use of water resources [16], soil health problems [17], energy return [18], and chemical fertilizer problems [19]. Social sustainability reflected as the development of the bioenergy industry is likely to create new employment opportunities and bring greater economic vitality in rural areas [20-22]. Therefore, the social sustainability of the bioenergy industry emphasizes how to improve social welfare, including promoting employment, poverty reduction, and indirect effects on land crops, reducing impact on social public resources, product liability issues, safeguarding public health, and food safety issues.

\subsection{Multiobjective Supply Chain Model and Solving Method.} The multiobjective supply chain optimization model is mainly divided into linear model and nonlinear model. According to the current research, most multiobjective supply chain optimization models are biobjective linear models. Many authors considered economic goals as traditional objective functions, while environmental or social goals are seen as extensions of traditional single-objective models. A common modeling approach is to consider an economic goal and an environmental goal. Chaabane et al. [23] proposed a biobjective model for the supply chain design of aluminum products, which included the part of carbon credits in the economic target and took the minimization of greenhouse gas emissions as the second objective. The model also takes inventory control decision into account. Akgul et al. [24] proposed a multicycle, multiproduct mixed integer linear programming model to optimize the economic and environmental problems of biofuel supply chain. All phases of the biofuel life cycle, such as planting, transportation, and production, are included in the model. Quariguasi [25] proposed a two-objective model to assess the material flow and production capacity of each plant to select the most suitable terminal substitute for use. Gosalbe et al. [26] designed a biobjective mixed integer linear programming model for hydrogen supply chain to study the impact of hydrogen network operation on climate 
change. In the chance constrained programming, the model is embedded with the probability that satisfies the uncertain constraint. Hugo et al. took into account the expansion of production capacity in their model also [27]. Govindan et al. [28] studied the two-stage multivehicle routing problem with time window to optimize the sustainable supply chain network of perishable food. They propose a deterministic model that incorporates two goals: an economic goal to minimize all costs and an environmental goal to minimize emissions from building facilities, distributing facilities, and transporting between facilities. Very few models have more than three objective functions. Erkut et al. [29] developed a multistandard facility site selection model for municipal solid waste management in northern Greece. Their mixed integer linear programming model includes five objective functions: one is the minimum total cost of facility implementation, and four are environmental impact targets (greenhouse gas effects, landfills, energy, and material recovery). Solutions to the model include technology sites, material recovery facilities, location selection of incinerators and sanitary landfills, and solid waste flows between these sites. Only a few two-objective models are nonlinear. Due to economies of scale, Zhang et al. [30] proposed a nonlinear model with $\mathrm{CO}_{2}$ emission objective caused by transportation. The nonlinear model is usually linearized; for example, Yue et al. [31, 32] used Charnes-Cooper transform and Glover to linearly transform the nonlinear model.

The current methods to solve the multiobjective supply chain optimization model mainly include the following: (1) weighted summation. The most straightforward way to deal with multiobjective models is to weight each criterion and then minimize the weighted sum of all criteria. The main advantage of this method is that single-objective modeling can be used to solve multiobjective problems. The disadvantage is that this modeling may not represent the interest of decision makers and may modify the Pareto structure of the problem [33]. (2) Pareto optimization method. The Pareto optimization method is often achieved by $\mathcal{E}$-constraint; that is, while prioritizing the main goal, other goals are expressed as constraints [34]. By repairing various constraint values, the Pareto frontier is approximated. This method is very suitable for extending a single target economic value to a dual target model that integrates environmental or social standards. By using economic models as the main objective, this approach enables decision makers to measure the economic impact of environmental or social constraints [35]. (3) Multistandard decision analysis and interactive methods. Multicriteria decision analysis can handle more environmental and social standards. When the number of objective functions increases and decision makers want to participate in building solutions, interactive methods are usually preferred [36].

In general, the optimization of biofuel supply chain is extremely important in the development system of the bioenergy industry. Scholars at home and abroad have done extensive research on theories and methods of biofuel supply chain optimization, especially in the areas of biofuel supply chain site selection and vehicle routing (using straw as raw material) for in-depth analysis. However, it is insufficient to discuss the theory of supply chain optimization using kitchen waste as raw materials, especially the design of sustainable supply chain, the construction of multiobjective optimization model, and solutions of biofuel supply chain model.

\section{Problem Description}

The biofuel industry needs to design its supply chain to operate efficiently as the same as each production-distribution system. This paper considering the multistage biodiesel supply chain makes decisions on the supply, distribution, pretreatment facilities, and the location and capacity of biodiesel refineries with kitchen waste as the raw material. The structure of sustainable WCO for biodiesel supply chain is shown in Figure 2.

Figure 2 shows the operation processes of taking kitchen waste as raw material to produce biodiesel. Kitchen waste is provided by the restaurant, and biodiesel operator using garbage truck transport takes kitchen waste to pretreatment facility. After preprocessing, the waste cooking oil is transported to biodiesel refineries to produce biodiesel. Then, biodiesel is transported to distribution service to be blended with diesel oil. As mentioned earlier, the supply chain of biodiesel from kitchen waste is different from that of a traditional biofuel supply chain. Therefore, this research considers the four-level network structure of biodiesel supply chain composed of kitchen waste acquisition, kitchen waste pretreatment, biodiesel production, and biodiesel sales. The first level is the kitchen waste supply point, that is, the restaurant; the second level is the kitchen waste pretreatment facility, where the food and kitchen waste is stored and converted into waste cooking oil; the third stage is biodiesel refinery, which converts the pretreated waste cooking oil into biodiesel. The fourth level is the biodiesel demand point, where the petrochemical refinery is the blending facility of biodiesel and diesel. The diesel demand can cause the change in the biodiesel demand. Through the optimization of biodiesel supply chain in this mode, the objectives of the supply chain can be minimized.

Assuming the location and output of the supply point are known, it can be seen from Figure 2 that all the kitchen waste provided to biodiesel operators from the supply point is available. Then, kitchen waste is transported to the pretreatment facility, where kitchen waste is collected and stored. When the supply is high due to changes in the supply of kitchen waste caused by the environment, holidays, and other factors, the pretreatment facility can temporarily store the kitchen waste in these facilities waiting for demand. The pretreated waste cooking oil is transported to the biodiesel refinery. Biodiesel refineries convert it to biodiesel. Unlike pretreatment facilities, biodiesel refineries are larger and more complex, and it costs much money to build and operate the refineries. Biodiesel refineries produce, sell, and ship biodiesel to some large petrochemical refineries. Assuming a certain number of large biodiesel refinery blending facilities have already existed, in this condition, the location and demand for biodiesel are known. In biodiesel refineries, regular diesel is blended with biodiesel and then transported 


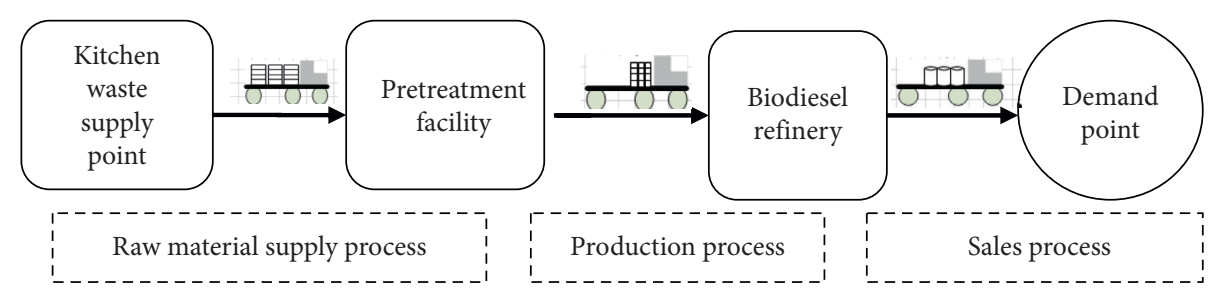

Figure 2: Sustainable WCO for biodiesel supply chain structure.

to petrol stations. Based on this information, the problems to be solved by designing the supply chain model include the following: the determination of the quantity, location, and capacity of kitchen waste pretreatment facilities; the location of the biodiesel refinery and its capacity to store the waste cooking oil and biodiesel; the amount of kitchen waste which the restaurant provides to each pretreatment facility; the quantity of waste cooking oil provided to the biodiesel refinery by each pretreatment facility; and the biodiesel production quantity. The network structure design and management plan of the supply chain affect each other. The location of pretreatment facilities and refineries determines the operation cost, which in turn affects the area and amount of kitchen waste collection. By establishing mixed integer linear programming (MILP) model and designing supply chain network, costs are reduced and overall profitability is improved.

3.1. Model Construction. The objectives of the mixed integer programming model for the optimization of the sustainable biofuels supply chain network using kitchen waste as raw materials include three parts: economic objectives, environmental objectives, and social objectives. The important assumptions in the model include the following: (1) the general annual operating cost is unchanged, which is not related to the processing and transferring of kitchen waste; (2) all final products are within the city, and the delivery time is not limited; (3) there are enough trucks to carry the collected kitchen waste; (4) urban traffic will not be affected by traffic jams, rush hours, etc.; (5) and the cost of facility construction is calculated at a specific annual interest rate. The symbols used in the model are shown in Table 1.

3.2. Objective 1: Economic Objective. The economic objective is to minimize the economic cost of the sustainable biodiesel supply chain system. Sustainable biodiesel supply chain economy target decision contains construction costs of pretreatment facilities and biodiesel refinery, pretreatment and storage cost of kitchen waste pretreatment facilities, production and storage costs of biodiesel refineries, and transportation cost between four facilities of supply point, pretreatment, refineries, and biodiesel demand point:

$$
\begin{aligned}
F_{1}= & \operatorname{Min} \sum_{t \in T}\left[\sum_{i \in I} \sum_{j \in J} c^{f d} \times d_{i j} \times q_{i j t}+\sum_{j \in J} \sum_{k \in K} c^{w d} \times d_{j k} \times q_{j k t}+\sum_{k \in K} \sum_{o \in O} c^{b d} \times d_{k o} \times q_{k o t}\right] \\
& +\sum_{j \in J} f_{j} \times Y_{j}+\sum_{k \in K} \sum_{l \in L} f_{k l} \times Z_{k l} \\
& +\sum_{j \in J} \sum_{t \in T} \mathrm{CPR} \times R_{j t}+\sum_{k \in K} \sum_{t \in T} \mathrm{CBP} \times R_{k t} \\
& +\sum_{t \in T}\left[\sum_{j \in J} \mathrm{CFS} \times S_{j t}^{f}+\sum_{k \in K} \mathrm{CWS} \times S_{k t}^{w}+\sum_{k \in K} \mathrm{CBS} \times S_{k t}^{b}\right] .
\end{aligned}
$$

3.3. Objective 2: Environmental Objective. Objective 2 mainly takes carbon emissions as an environmental impact indicator and studies the minimization of carbon emissions in the supply chain of sustainable biodiesel from the perspective of life cycle. It considers carbon emissions in the process of kitchen waste collection, pretreatment, biodiesel production, and transportation. Transporting carbon emissions consist of three components: transporting kitchen waste from restaurants to pretreatment facilities, transporting waste cooking oil from pretreatment facilities to biodiesel refineries, and transporting biodiesel from refineries to demand point:

$$
\begin{aligned}
F_{2}= & \operatorname{Min} \sum_{i \in I} \sum_{t \in T} \mathrm{EHV} \times \Phi_{i t}+\sum_{t \in T} \sum_{i \in I} \sum_{j \in J} \mathrm{ECT} \times d_{i j} \times q_{i j t} \\
& +\sum_{t \in T} \sum_{j \in J} \sum_{k \in K} \mathrm{ECT} \times d_{j k} \times q_{j k t}+\sum_{t \in T} \sum_{k \in K} \sum_{o \in O} \mathrm{ECT} \times d_{k o} \times q_{k o t} \\
& +\sum_{j \in J} \sum_{t \in T} \mathrm{EBD} \times R_{j t}+\sum_{k \in K} \sum_{t \in T} \mathrm{EPD} \times R_{k t} .
\end{aligned}
$$

3.4. Objective 3: Social Objective. On the one hand, kitchen waste can be used to produce biodiesel. On the other hand, it can also be illegally used to produce gutter oil, which will 
TABLE 1: Notation.

\begin{tabular}{|c|c|}
\hline Set & \\
\hline$I$ & Set of kitchen waste supply point $i$ \\
\hline$J$ & Set of potential pretreatment facility locations $j$ \\
\hline K & Set of potential biodiesel refinery site $k$ \\
\hline$O$ & Set of biodiesel demand location $o$ \\
\hline$L$ & Set of biodiesel refinery size level $l$ \\
\hline$T$ & The set of $t$ in time \\
\hline Paran & \\
\hline$d_{i j}$ & Distance from kitchen waste supply point $i$ to pretreatment facility $j$ \\
\hline$d_{j k}$ & Distance from pretreatment facility $j$ to biodiesel refinery $k$ \\
\hline$d_{k o}$ & Distance from biodiesel refinery $k$ to biodiesel demand point $o$ \\
\hline$\Phi_{i t}$ & Supply of restaurant kitchen waste $i$ at time $t$ \\
\hline$D_{o t}$ & Demand of biodiesel demand point $o$ at time $t$ \\
\hline$M^{c}$ & Kitchen waste processing capacity of the pretreatment facility $j$ \\
\hline$M_{l}^{p}$ & Waste oil processing capacity of a biodiesel refinery of size $l$ \\
\hline$M^{c f}$ & Storage capacity of the pretreatment facility $j$ \\
\hline$M_{l}^{p w}$ & Storage capacity of waste cooking oil from a biodiesel refinery of size $l$ \\
\hline$M_{l}^{p b}$ & Storage capacity of biodiesel from a biodiesel refinery of size $l$ \\
\hline CPR & Pretreatment facility handles the cost of unit kitchen waste \\
\hline CBP & Cost of process of waste cooking oil per unit at a biodiesel refinery \\
\hline$c^{f d}$ & Transportation cost of per unit kitchen waste \\
\hline$c^{w d}$ & Transportation cost of per unit waste cooking oil \\
\hline$c^{b d}$ & Distance transport cost of per unit biodiesel \\
\hline CFS & Storage cost of per unit kitchen waste \\
\hline CWS & Storage cost of per unit waste cooking oil \\
\hline CBS & Storage cost of per unit biodiesel \\
\hline$f_{j}$ & Fixed construction cost of the pretreatment facility at $j$ \\
\hline$f_{k l}$ & Fixed construction cost of a biodiesel refinery of size $l$ at site $k$ \\
\hline $\mathrm{EHV}$ & Carbon emission of unit kitchen waste collection \\
\hline EBD & Carbon emission of unit kitchen waste pretreatment \\
\hline $\mathrm{EPD}$ & Carbon emission of unit waste cooking oil processing \\
\hline ECT & Carbon emissions per kilometer transported by trucks \\
\hline$\mu$ & Transformation factor of kitchen waste to waste cooking oil \\
\hline$\beta$ & Conversion factors of waste cooking oil to biodiesel \\
\hline Decisi & \\
\hline$q_{i j t}$ & Quantity of kitchen waste supply point transported to pretreatment facility $j$ at time $t$ \\
\hline$q_{j k t}$ & Quantity of pretreatment facility $j$ delivered to biodiesel refinery $k$ at time $t$ \\
\hline$q_{k o t}$ & Quantity of biodiesel refinery $k$ transported to biodiesel demand point $o$ at time $t$ \\
\hline$Y_{j}$ & It is 1 when position $j$ is used to build the pretreatment plant; otherwise, it is 0 \\
\hline$Z_{k l}^{j}$ & It is 1 when location $k$ is used to build a refinery of size $l$; otherwise, it is 0 \\
\hline$R_{j t}$ & Quantity of kitchen waste processed by the pretreatment plant $j$ at time $t$ \\
\hline$R_{k t}$ & Quantity of waste oil treated by refinery $k$ at time $t$ \\
\hline$S_{j t}^{f^{l}}$ & Quantity of kitchen waste stored in the pretreatment facility $j$ at time $t$ \\
\hline$S_{k t}^{j t}$ & Quantity of waste oil stored in biodiesel refinery $k$ at time $t$ \\
\hline$S_{k t}^{b}$ & Quantity of biodiesel stored in biodiesel refinery $k$ at time $t$ \\
\hline
\end{tabular}

have a negative impact on human health. Therefore, kitchen waste that is not recycled for production by biodiesel processing enterprises is likely to enter the supply chain of waste cooking oil production through various illegal means. The social goal of this paper is to minimize the amount of unused kitchen waste:

$$
F_{3}=\operatorname{Min} \sum_{i \in I} \sum_{t \in T}\left(\Phi_{i t}-\sum_{j \in J} q_{i j t}\right) .
$$

3.5. Constraint Set. The constraints on kitchen waste supply points, pretreatment facilities, biodiesel refineries, and biodiesel demand points are as follows.
Food and kitchen waste supply point constraints:

$$
\sum_{j \in J} q_{i j t} \leq \Phi_{i t}, \quad \forall i \in I, t \in T
$$

Constraint (4) is that the total amount of kitchen waste transported by the restaurant cannot exceed the total supply.

Pretreatment facility constraints:

$$
\begin{aligned}
\sum_{i \in I} q_{i j t} \leq M^{c f} \times Y_{j}, & \forall j \in J, t \in T, \\
S_{j t}^{f} \leq M^{c f} \times Y_{j}, & \forall j \in J, t \in T, \\
\mu \times R_{j t} \leq M^{c} \times Y_{j}, & \forall j \in J, t \in T,
\end{aligned}
$$




$$
\begin{gathered}
\sum_{i \in I} q_{i j t}+S_{j(t-1)}^{f}=R_{j t}+S_{j t}^{f}, \quad \forall j \in J, t \in T, \\
\sum_{k \in K} q_{j k t}=\mu \times R_{j t}, \quad \forall j \in J, t \in T .
\end{gathered}
$$

Constraint (5) ensures that kitchen waste is transported to the pretreatment facility only when the site is selected and specifies the capacity limits for opening the pretreatment facility at the site. Constraint (6) is the limit of the storage capacity of kitchen waste in the pretreatment facility. Constraint (7) is the limitation of the process capacity of the pretreatment facility. If the pretreatment facility is not selected, the constraint is also set to zero. Since the pretreatment facility can only store kitchen waste, constraints (8) and (9) ensure the balance between the amount of kitchen waste and waste cooking oil in and out of the pretreatment facility.

Biodiesel refinery constraints:

$$
\begin{gathered}
\sum_{j \in J} q_{j k t} \leq \sum_{l \in L} M_{l}^{p w} \times Z_{k l}, \quad \forall k \in K, t \in T, \\
S_{k t}^{w} \leq \sum_{l \in L} M_{l}^{p w} \times Z_{k l}, \quad \forall k \in K, t \in T, \\
S_{k t}^{b} \leq \sum_{l \in L} M_{l}^{p b} \times Z_{k l}, \quad \forall k \in K, t \in T, \\
\beta \times R_{k t} \leq \sum_{l \in L} M_{l}^{p} \times Z_{k l}, \quad \forall k \in K, t \in T, \\
\sum_{j \in J} q_{j k t}+S_{k(t-1)}^{w}=R_{k t}+S_{k t}^{W}, \quad \forall k \in K, t \in T, \\
\sum_{o \in O} q_{k o t}+S_{k t}^{b}=\beta \times R_{k t}+S_{k(t-1)}^{b}, \quad \forall k \in K, t \in T .
\end{gathered}
$$

Constraint (10) ensures that the pretreated waste cooking oil is transported to the biodiesel refinery only when the refinery is selected. At the same time, the capacity limits for the opening of the biodiesel refinery are limited. Constraint (11) has the limits on the inventory capacity of the pretreated waste cooking oil in the biodiesel refinery. Constraint (12) is the limit on biodiesel storage capacity of biodiesel refineries. Constraint (13) has limits on biodiesel production capacity of biodiesel refineries. If the biodiesel refinery is not selected, the constraint is also set to zero. Constraint (14) is to ensure the balance of the amount of pretreated waste cooking oil in and out of the biodiesel refinery. Constraint (15) is to ensure a balance of the amount of biodiesel in and out of a biodiesel refinery.

Biodiesel demand point constraint: constraint (16) is that the total amount of biodiesel transported from the biodiesel demand point is more than or equal to the total demand:

$$
\sum_{k \in K} q_{k o t} \geq D_{o t}, \quad \forall o \in O, t \in T .
$$

Integer and nonnegative constraints: constraints $(17) \sim(19)$ are nonnegative and integrity requirements for decision variables:

$$
\begin{gathered}
\sum_{l \in L} Z_{k l} \leq 1, \quad \forall k \in K, \\
Z_{k l}, Y_{j} \in\{0,1\}, \quad \forall j, k, l, \\
q_{i j t}, q_{j k t}, q_{k o t}, R_{j t}, R_{k t}, S_{j t}^{f}, S_{k t}^{w}, S_{k t}^{b} \geq 0, \quad \forall i, j, k, o, t .
\end{gathered}
$$

3.6. Solving Method. For optimization problems with multiple different goals, appropriate tradeoffs between different goals are often required. Multiobjective optimization problems have some common solving methods. For example, the double objective optimization problem, when solving method based on decision makers, prefers to choose a more important target as a single goal, first of all solving for obtaining a target and then taking the target value as a constraint of the original problem solving another singleobjective optimization problem. Some scholars directly set the weights of different goals according to the preference of decision makers and then combine multiple goals into a composite goal for solving. Obviously, both methods require knowledge of decision makers' preferences, but in some cases, this is difficult to obtain, and the results are difficult to meet the needs of different decision makers at the same time. An effective way to solve multiobjective optimization problems is Pareto optimality based on the concept of nondominant solutions. Improving any objective function on the basis of the nondominant solution (Pareto solution) will inevitably weaken at least one other objective function [37]. As shown in Figure 3, the Pareto front composed of uniformly distributed Pareto solution sets can well express the solution space. The acquisition of Pareto front can provide decision makers with more cognition and awareness of the tradeoff between different objectives of the optimization problem [38].

The calculation amount involved in the optimization of biodiesel supply chain mainly depends on the number of network nodes. Here, we use $N$ which represents the number of network nodes and $G$ the number of construction levels of facilities. Therefore, the possible site selection scheme is $G \times 2^{N}$ in this paper. When the number of network nodes reaches dozens (in the case of this paper, the number of network nodes is close to 1500), the times of transportation distribution will be up to a million times. Because the cases in this paper cannot obtain exact solutions in an acceptable time, heuristic algorithms (such as genetic algorithms) must be used. For the multiobjective optimization problem, the best method is to use Pareto optimization. To find a set of solutions which can express the Pareto optimal frontier, we need to get a noninferior solution and the distribution of noninferior solution should be as uniform as possible. To solve the above two problems, this paper 


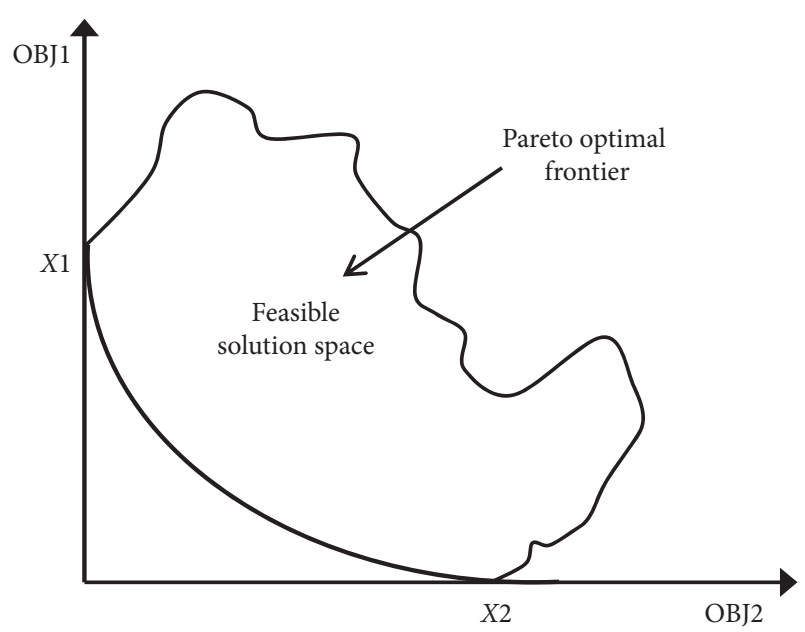

FIgURE 3: Schematic diagram of Pareto optimal frontier.

adopts the genetic (NSGAII) algorithm with elite strategy to solve the problem. The NSGAII algorithm can carry out the strategy design in the multiobjective genetic algorithm, which includes the fast noninferior sorting strategy, the fastcrowding distance estimation strategy, the selection strategy based on partial order, and the elite retention strategy. Because the NSGAII algorithm gives more noninferior solutions in a single calculation, it can better describe the Pareto front of the problem. In terms of the quality of the solution, the NSGAII algorithm can effectively solve the multicycle dynamic logistics network optimization problem, especially including the inventory and capacity decision in the multiphase plan.

\section{Case Study}

This paper takes the kitchen waste in Jiangsu Province as an example for analysis. In this case, the data of restaurant location, facility location, restaurant supply, and biodiesel demand are mainly used. Before analyzing the model results, the steps for processing the raw data to generate the input data used in the actual application are described. The locations of 104,922 restaurants and 748 municipal solid waste centers in Jiangsu Province were obtained through Baidu map. These restaurants and garbage stations were cleaned through SQL database, and 60,259 restaurants and 446 municipal solid waste collection and transfer centers were identified after screening and filtering. The data set includes the name, address, longitude, and latitude information of all data points. The restaurant serves as a source of kitchen waste, and the future kitchen waste pretreatment facility will be built on top of the existing MSW transfer center, with 56 prefecture-level cities selected as potential locations for biodiesel refineries. There is no comprehensive data set on kitchen waste production in China, and most kitchen waste statistics are based on random sampling rather than actual kitchen waste data from individual restaurants. Through GIS data, we can learn about the restaurant, but we do not know the size, so each restaurant food garbage cannot be calculated. So, this paper uses the K-means algorithm randomly sampling the data set to generate the typical database and then calculate the kitchen waste supply according to the clustering of database. Finally, the distance data in this paper are calculated by the matrix of ArcGIS starting point and destination.

\subsection{Data Sources}

4.1.1. Kitchen Waste Supply in Jiangsu Province. In this paper, all the restaurants (about 60,259 restaurants) in Jiangsu were selected as the kitchen waste suppliers. However, direct distribution of these restaurants is very difficult and time-consuming, so this paper uses the $k$-means clustering algorithm to divide them into several regions according to latitude and longitude (800 regions as shown in Figure 4).

In addition, it is reported that the average daily kitchen waste of the restaurant was set at 0.07 tons in 2017 [39]. At present, restaurants supply kitchen waste for biodiesel production accounting for about a quarter of all restaurants. Based on the calculation of all restaurants operating 365 days a year, the amount of kitchen waste that can be collected in the current period is calculated, as shown in Table 2 (only 10 points are shown due to space restrictions). The current period is set as the first period, and the supply in this period is the baseline supply of kitchen waste. Using some forecasting methods, the estimated supply value of the remaining 9 cycles within the planned scope is obtained based on the basic supply.

4.1.2. Biodiesel Demand in Jiangsu Province. The demand for biodiesel basically occurs when petrochemical refineries are blending biodiesel and diesel. Therefore, in order to calculate the biodiesel demand, this paper first determines the existing petrochemical refineries in Jiangsu Province. As of 2019, there are altogether 5 large-scale petrochemical refineries in Jiangsu Province producing diesel. It is assumed that these five facilities serve as the demand points for biodiesel, as shown in Figure 5. The diesel production capacity and the location of these refineries were obtained from the annual refinery report, and at the same time, $33 \%$ of the total capacity of these refineries is used to meet the production needs of B5 (5\% biodiesel blend) diesel in Jiangsu Province. These values are used to obtain the basic biodiesel demand values for each blending facility. Based on the considered multicycle planning perspective, this paper obtained the demand for the remaining nine cycles through the prediction of the basic demand values, as shown in Table 3 .

4.1.3. Parameters of the Alternative Pretreatment Facilities. In this research, $446 \mathrm{MSW}$ transfer centers are selected as alternative pretreatment plants through data screening. It is assumed that the future kitchen waste pretreatment facility station will be built in the existing MSW transfer center, as shown in Figure 6. According to the literature, relevant parameters of the pretreatment facility are summarized in Table 4. 


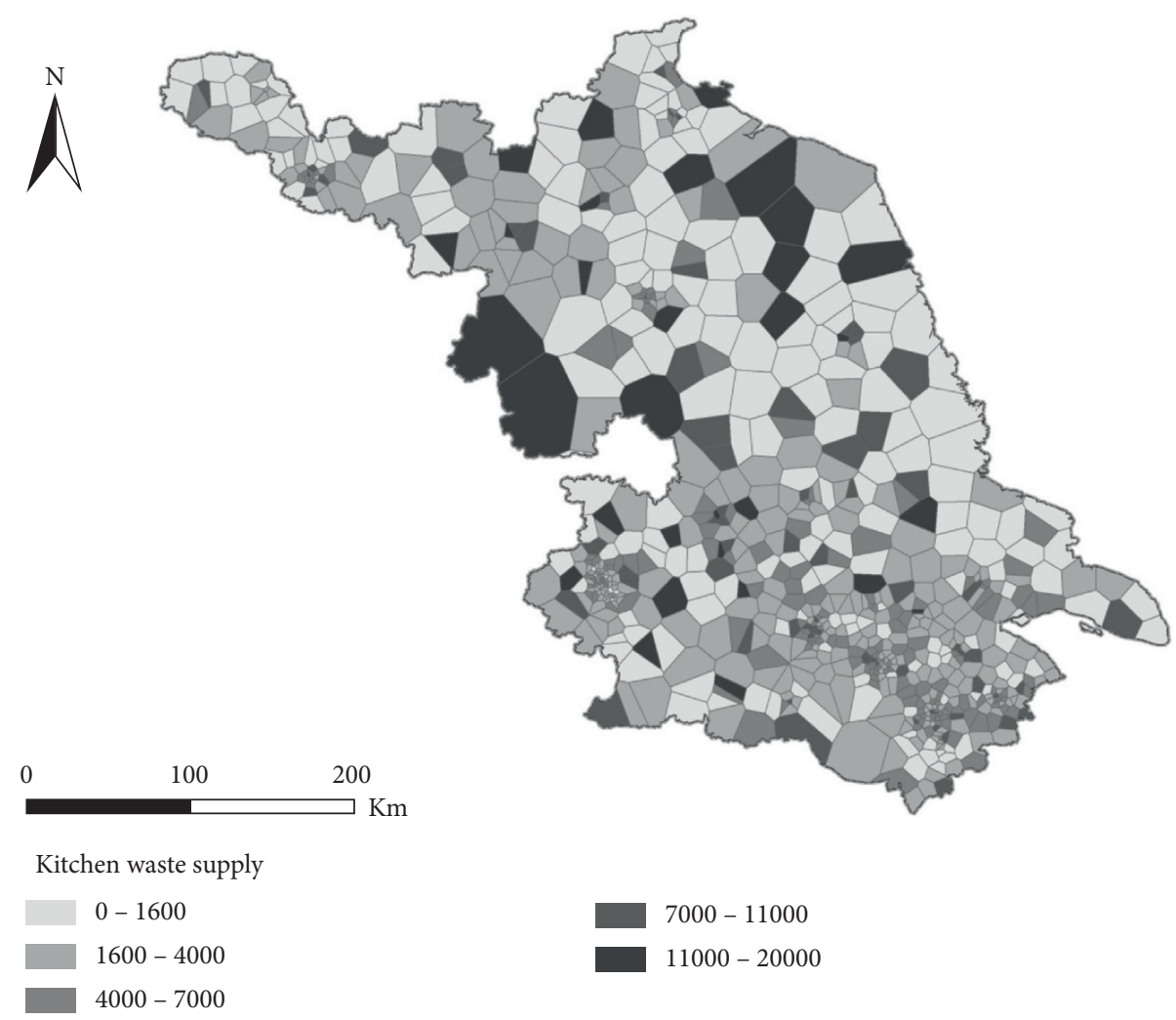

FIgURE 4: Food and beverage enterprises in Jiangsu Province kitchen waste supply situation.

TABle 2: Regional basic information of catering enterprises in Jiangsu Province.

\begin{tabular}{|c|c|c|c|c|}
\hline Category number & Number of catering enterprises (quantity) & Kitchen waste supply (tons) & Longitude mean & Latitude mean \\
\hline 1 & 58 & 1481.9 & 119.25 & 34.67 \\
\hline 2 & 48 & 1226.4 & 120.18 & 31.72 \\
\hline 3 & 39 & 996.45 & 117.32 & 34.19 \\
\hline 4 & 36 & 919.8 & 121.10 & 31.66 \\
\hline 5 & 13 & 332.15 & 118.57 & 32.13 \\
\hline 6 & 55 & 1405.25 & 118.93 & 32.39 \\
\hline 7 & 83 & 2120.65 & 120.64 & 31.17 \\
\hline 8 & 59 & 1507.45 & 117.13 & 34.3 \\
\hline 9 & 47 & 1200.85 & 119.10 & 33.60 \\
\hline 10 & 48 & 1226.40 & 120.11 & 32.52 \\
\hline
\end{tabular}

4.2. Parameters of the Crude Diesel Refinery. All the 56 counties and cities in Jiangsu Province will be potential candidates for biodiesel refineries, as shown in Figure 7. Zhang [40] estimates that the total investment cost of a biodiesel refinery in China producing 350 tons of biodiesel per day will exceed RMB 70 million. In consideration of the factory project life of 20 years and a $10 \%$ interest rate, the paper estimates the salvage value of biodiesel refineries with depreciation rate and calculates the further biological refinery current net fixed cost. We assume there are three alternative capacities (L1 (small), L2 (medium), and L3 (large)) of biodiesel refinery for biodiesel refining and then get the following relevant parameters of biodiesel refineries in Table 5.
4.2.1. Other Parameters. There are other parameters in this study, as shown in Table 6.

4.3. Effectiveness Analysis of the Algorithm. This case study takes into account the 10-year cycle of the development of the biodiesel industry, in which the first cycle starts from the development of kitchen waste as raw material to produce biodiesel in Jiangsu Province in 2019. The figure above shows the iterative curve of the sum of the target values of the 10 cycles. According to the addition requirement of B5, the biodiesel demand of kitchen waste production is calculated to be 25,700 tons with the diesel demand of Jiangsu oil refinery. From the perspective of supply, this paper believes 


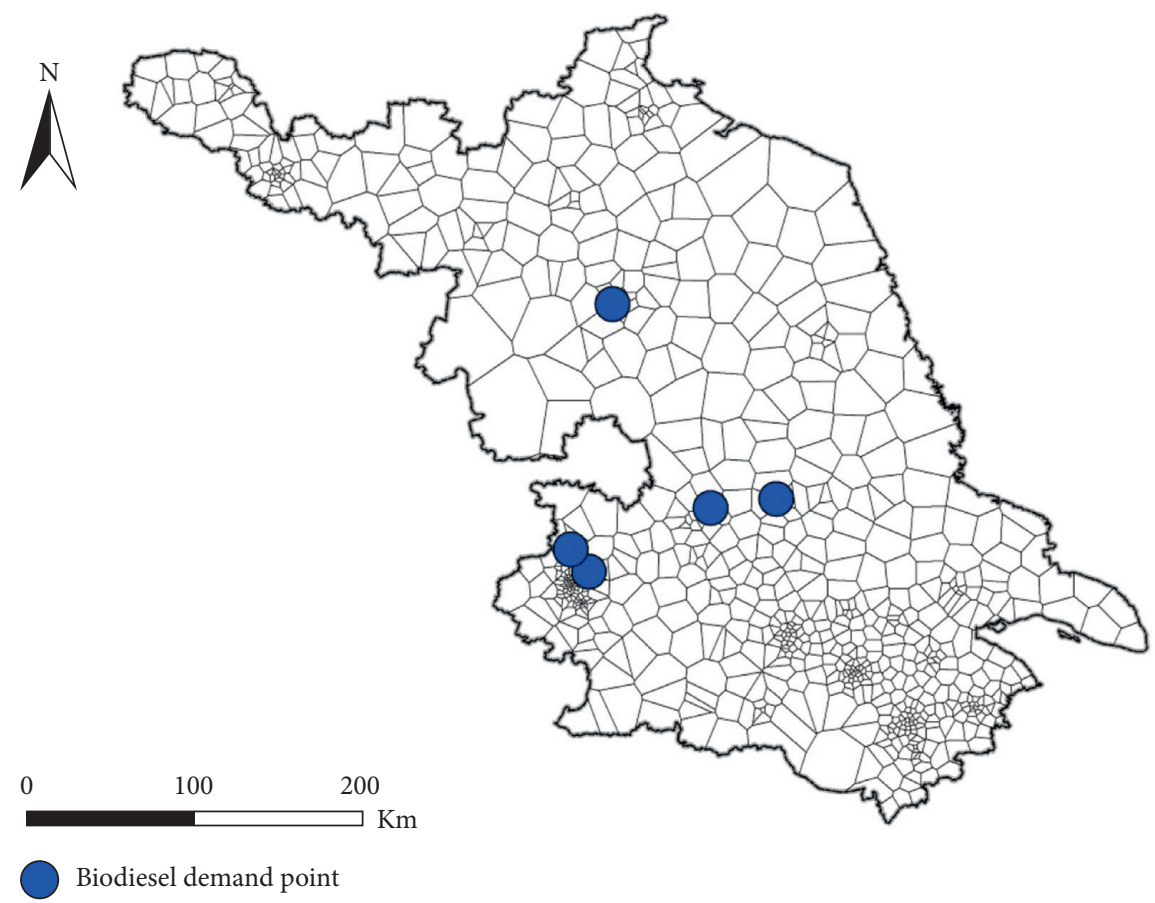

FIgURE 5: Biodiesel demand in Jiangsu Province.

Table 3: Biodiesel demand information of Jiangsu Province.

\begin{tabular}{|c|c|c|c|c|c|}
\hline \multirow{2}{*}{ Cycle $t$} & \multicolumn{5}{|c|}{ Demand point $o$} \\
\hline & 1 & 2 & 3 & 4 & 5 \\
\hline 1 & 1250.00 & 11250.00 & 7916.67 & 958.33 & 41.67 \\
\hline 2 & 1270.00 & 11187.50 & 8004.17 & 976.67 & 44.17 \\
\hline 3 & 1365.00 & 11713.33 & 8184.17 & 995.00 & 49.17 \\
\hline 4 & 1410.00 & 12240.83 & 8302.50 & 1013.33 & 52.50 \\
\hline 5 & 1467.50 & 12472.50 & 8436.25 & 1031.67 & 56.25 \\
\hline 6 & 1918.33 & 16396.78 & 11159.17 & 1363.33 & 72.50 \\
\hline 7 & 2144.40 & 18278.52 & 12402.56 & 1515.95 & 81.61 \\
\hline 8 & 2370.48 & 20160.25 & 13645.95 & 1668.57 & 90.71 \\
\hline 9 & 2596.55 & 22041.99 & 14889.35 & 1821.19 & 99.82 \\
\hline 10 & 2822.62 & 23923.73 & 16132.74 & 1973.81 & 108.93 \\
\hline
\end{tabular}

that all kitchen waste from restaurants in the province could be converted into biodiesel after being treated. Therefore, there is great room for the future development of biodiesel production from kitchen waste. The multiobjective mixed integer linear programming problem calculated in this case study is solved by using Matlab on a desktop computer with Intel $(R)$ Core (TM) i5-7500 CPU, using the optimization model as shown above.

To verify the distribution degree of the solution set of NSGAII algorithm, this paper takes three objective functions as fitness evaluation functions and obtains the iterative curves of the three objective functions, as shown in Figure 8. It can be seen that the curves converge after the iteration of 700 generations, and the objective function values are basically stable, indicating that the distribution degree of the noninferior solution of this algorithm is good. For this case, the whole solution process needs a total of 22012.24 seconds. The Pareto curve obtained is shown in Figure $8(\mathrm{~d})$.

\subsection{Result Analysis}

4.4.1. Analysis of Target Value Results. The analysis of objective results is mainly based on comparison of the optimal objective value for each cycle. The paper taking the economic objective as the main target and measuring the relationship between the environmental objective and the economic objective or social objective and the economic objective obtains the curves in Figures 9 and 10, respectively.

First, consider the tradeoff between economic and social objective. All the best solutions for economic and social objective are on the Pareto optimal curve. The part above the curve in Figure 9 is a suboptimal solution, and any solution below the curve is not feasible. As can be seen from the figure, as the size of the company shrinks and the annual total cost decreases, the amount of unused kitchen waste increases. Specifically, when the optimal total annual cost was reduced from about RMB289 million yuan to RMB283 


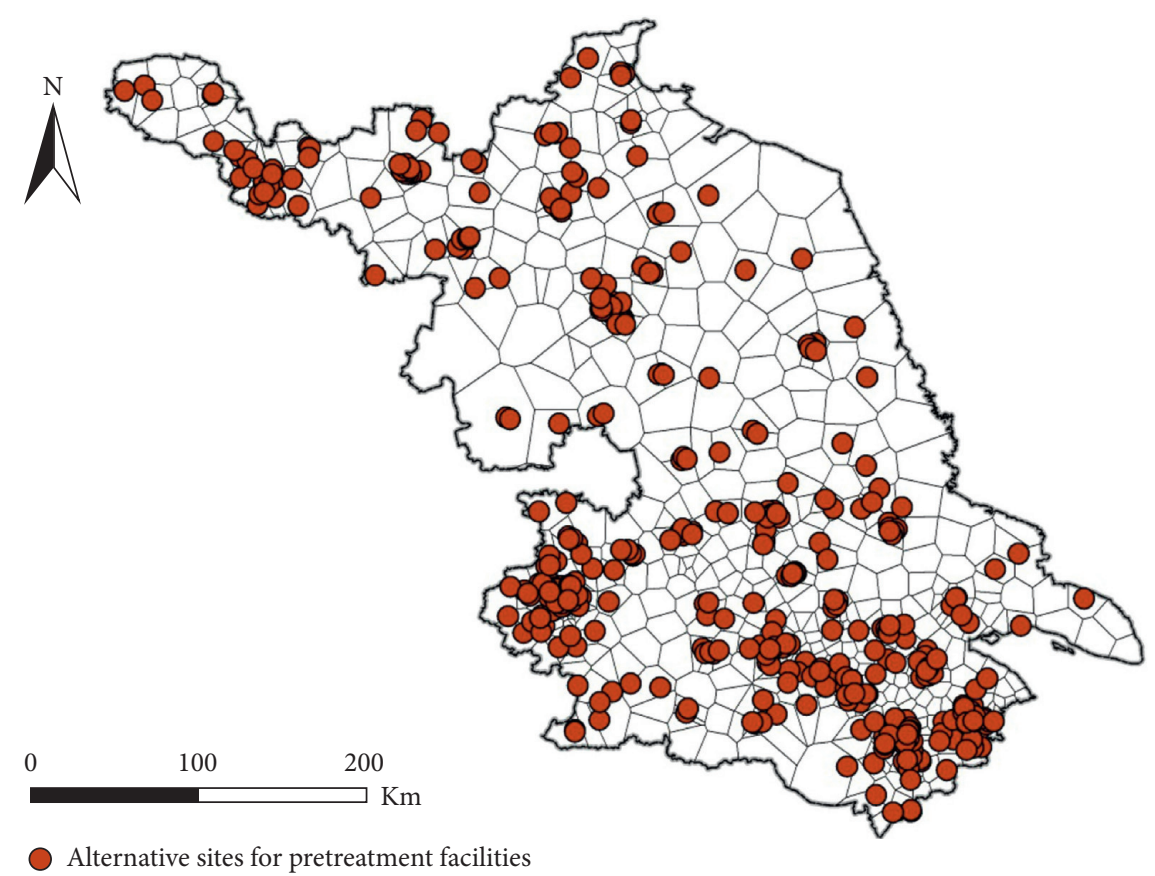

Figure 6: Alternative pretreatment facilities in Jiangsu Province.

TABle 4: Parameters of the pretreatment facility.

\begin{tabular}{lc}
\hline Parameters of the pretreatment facility & Parameter \\
value & Unit \\
\hline $\begin{array}{l}\text { Kitchen waste pretreatment capacity of the pretreatment facility is estimated according to the } \\
\text { processing force of a single oil and water processor and a single unit from } 5 \text { to } 100 \mathrm{~m}^{3} / \mathrm{hr}\end{array}$ & 100000 \\
$\begin{array}{l}\text { Storage capacity of kitchen waste of the pretreatment facility } M_{l}^{\text {pw }} \\
\text { Fixed construction cost of the pretreatment facility } f_{j}\end{array}$ & $300000 \quad \begin{array}{c}\text { Tons/year } \\
\text { Ten thousand } \\
\text { yuan }\end{array}$ \\
\hline
\end{tabular}

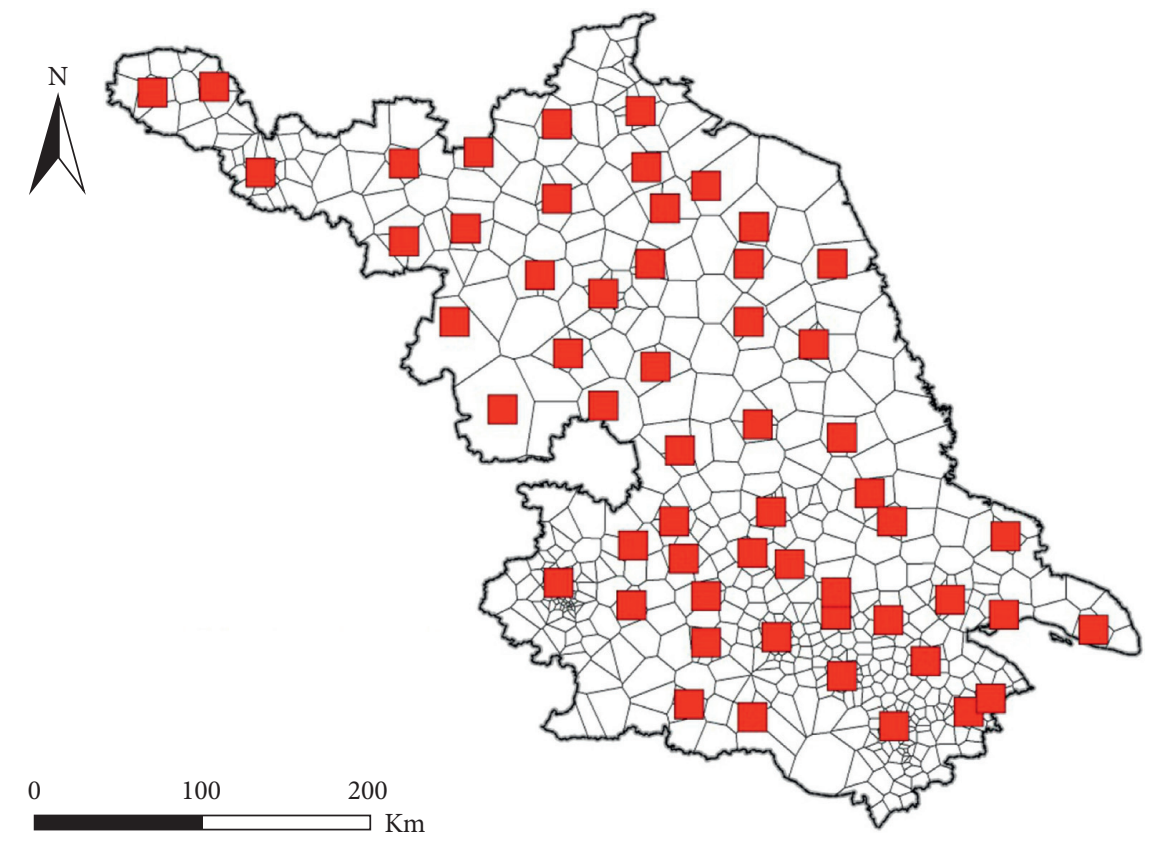

Biodiesel refinery alternative sites

FIgURe 7: Alternative locations of biodiesel refineries in Jiangsu Province. 
TABle 5: Parameters of biodiesel refining plants.

\begin{tabular}{|c|c|c|c|c|}
\hline \multirow{2}{*}{ Parameters of biodiesel refineries } & \multicolumn{3}{|c|}{ Scale } & \multirow{2}{*}{ Unit } \\
\hline & $L 1$ (small) & L2 (medium) & L3 (large) & \\
\hline Waste oil processing capacity of a biodiesel refinery of size $l M_{l}^{p}$ & 20000 & 40000 & 70000 & Ton \\
\hline Waste oil storage capacity of a biodiesel refinery of size $l M_{l}^{p w}$ & 7000 & 15000 & 25000 & Ton \\
\hline Biodiesel storage capacity of a biodiesel refinery of size $l M_{l}^{p b}$ & 7000 & 10000 & 20000 & Ton \\
\hline Fixed construction cost of a biorefinery at $k$ of size $l \mathrm{f}_{\mathrm{kl}}$ & 4000 & 7000 & 10000 & Ten thousand yuan \\
\hline
\end{tabular}

TABLE 6: Other parameters.

\begin{tabular}{|c|c|}
\hline Other parameters & Parameter value \\
\hline Conversion factor of kitchen waste to waste cooking oil is the separation rate of oil and water & $6.32 \%$ \\
\hline Conversion factor of waste cooking oil to biodiesel & $85 \%[41]$ \\
\hline Preprocessing facility preprocessing unit kitchen waste cost & 15 yuan/ton $[42]$ \\
\hline Cost per unit of waste cooking oil treated by a refinery & 1100 yuan/ton $[43]$ \\
\hline Cost of storing kitchen waste per unit & 50 yuan/ton \\
\hline Cost of storing a unit of waste cooking oil & 80 yuan/ton \\
\hline Cost of storing a unit of biodiesel & 125 yuan/ton \\
\hline Distance transportation cost of unit kitchen waste & 0.20 yuan/ton $/ \mathrm{km}[44]$ \\
\hline Distance transportation cost per unit of waste oil & $0.25 \mathrm{yuan} / \mathrm{ton} / \mathrm{km}[44]$ \\
\hline Distance transport cost per unit of biodiesel & 0.35 yuan $/$ ton $/ \mathrm{km}[44]$ \\
\hline Rate of greenhouse gas emissions from kitchen waste collection & $5.6 \mathrm{kgCO}_{2}$ eqv./ton \\
\hline Carbon emission of unit kitchen waste pretreatment & $12.6 \mathrm{kgCO}_{2}$ eqv./ton $[45]$ \\
\hline Carbon emission of waste oil from processing unit & $1465 \mathrm{kgCO}_{2}$ eqv./ton [46] \\
\hline Carbon emissions from transportation & $0.1215 \mathrm{kgCO}_{2} \mathrm{eqv} . / \mathrm{ton}[46]$ \\
\hline
\end{tabular}

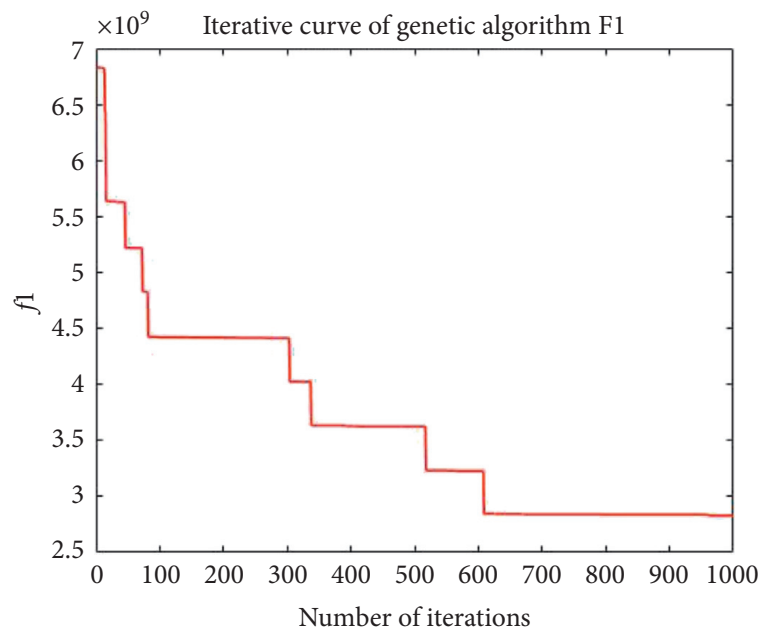

(a)

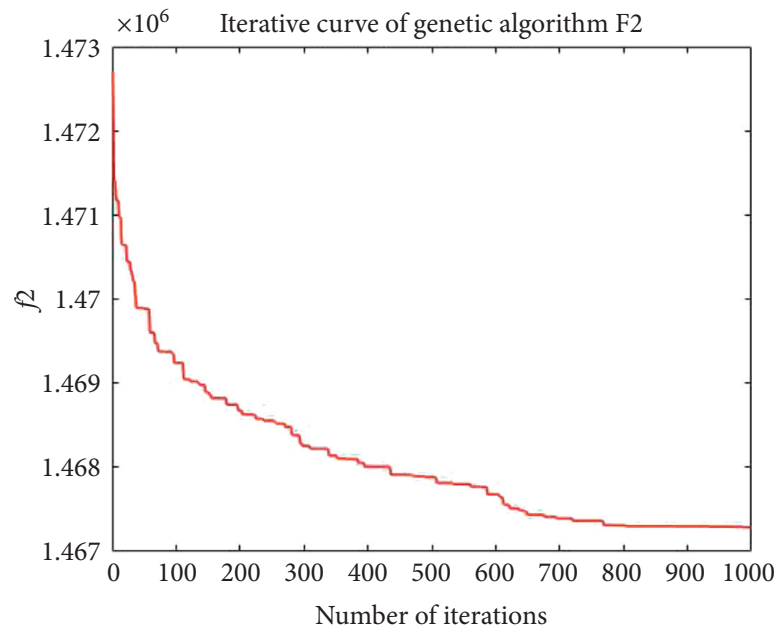

(b)

Figure 8: Continued. 


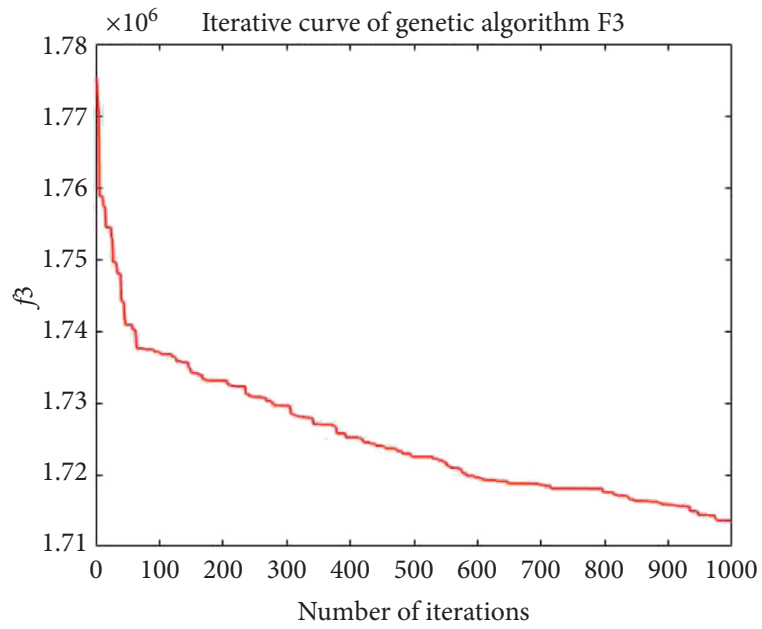

(c)

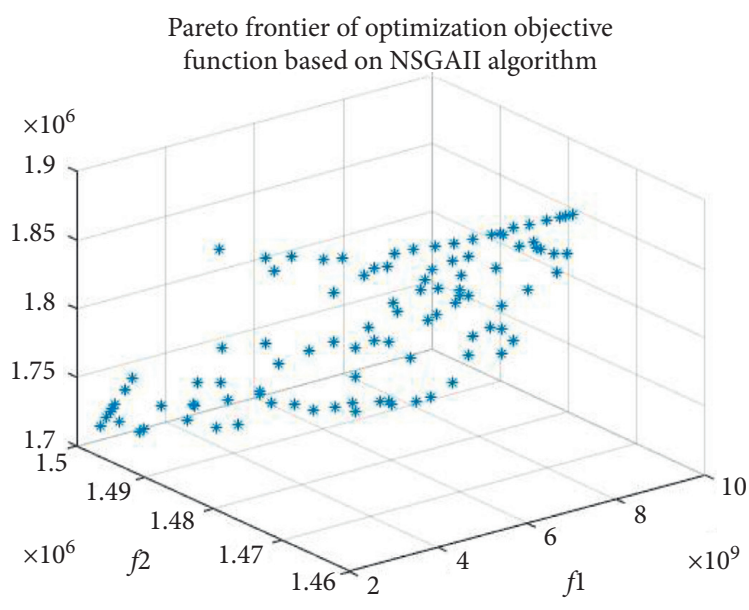

(d)

FIGURE 8: (a) Iterative curve of economic objectives. (b) Iterative curve of environmental objectives. (c) Iteration curve of social goals. (d) Pareto front diagram of the three objective functions.

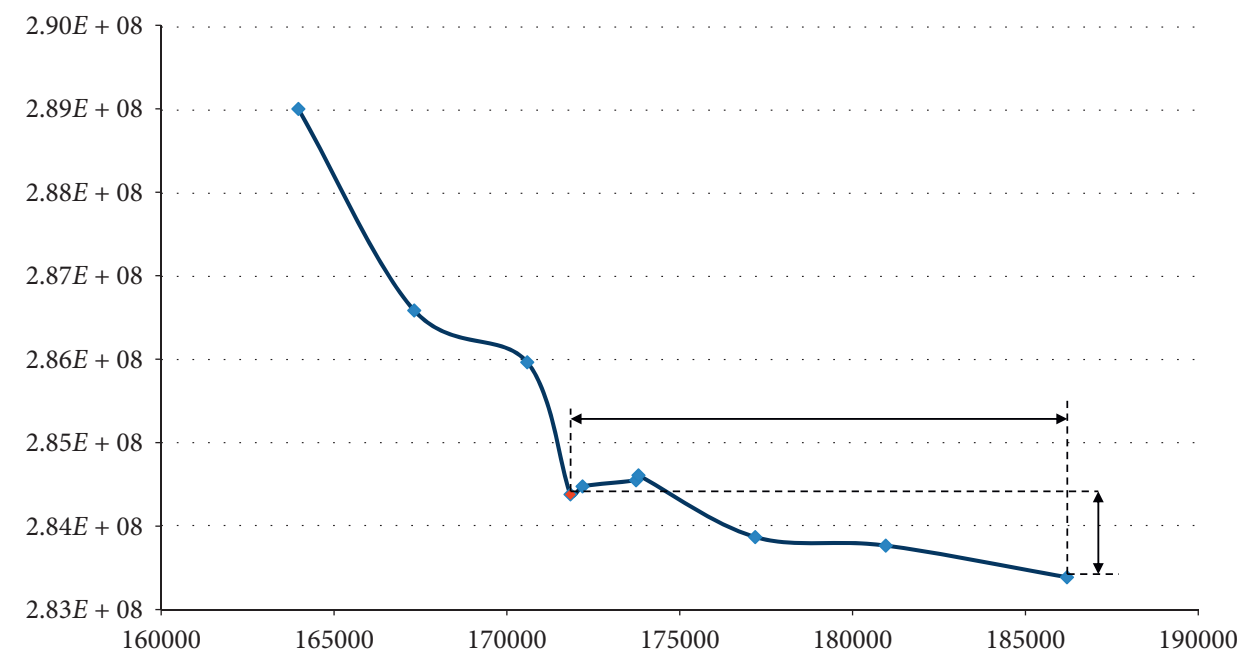

FIGURE 9: Pareto optimal curves of economic and social objectives.

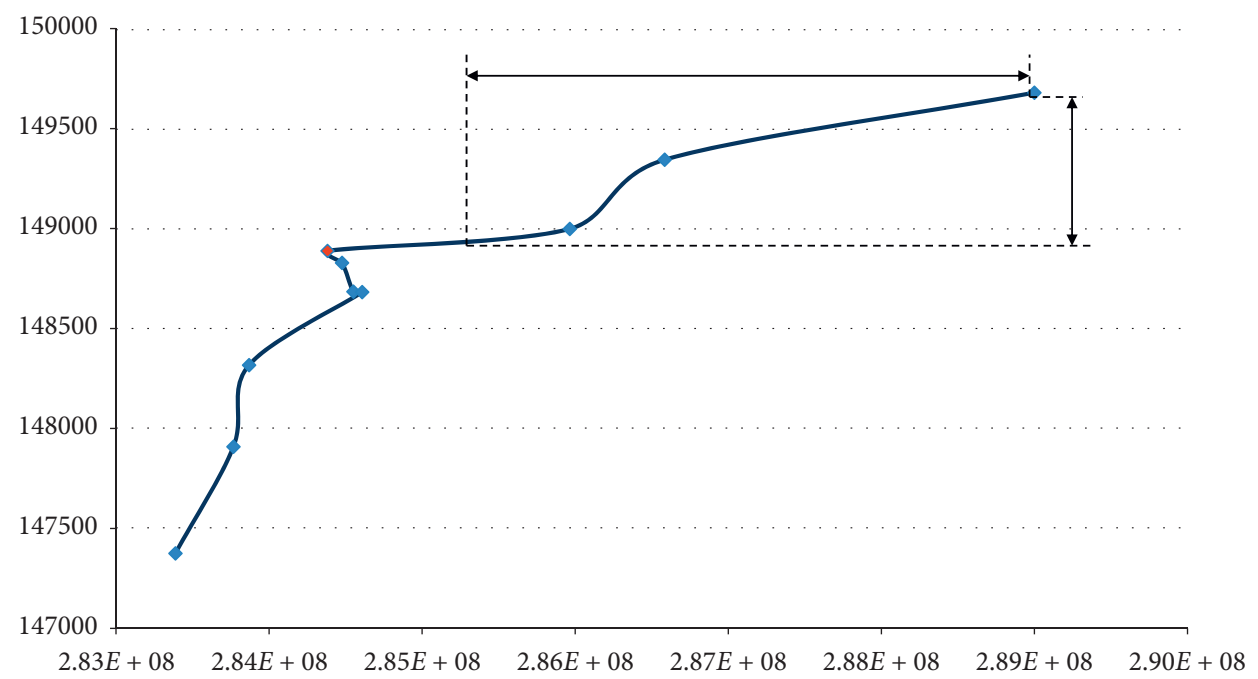

FIGURE 10: Pareto optimal curves of economic and environmental objectives. 


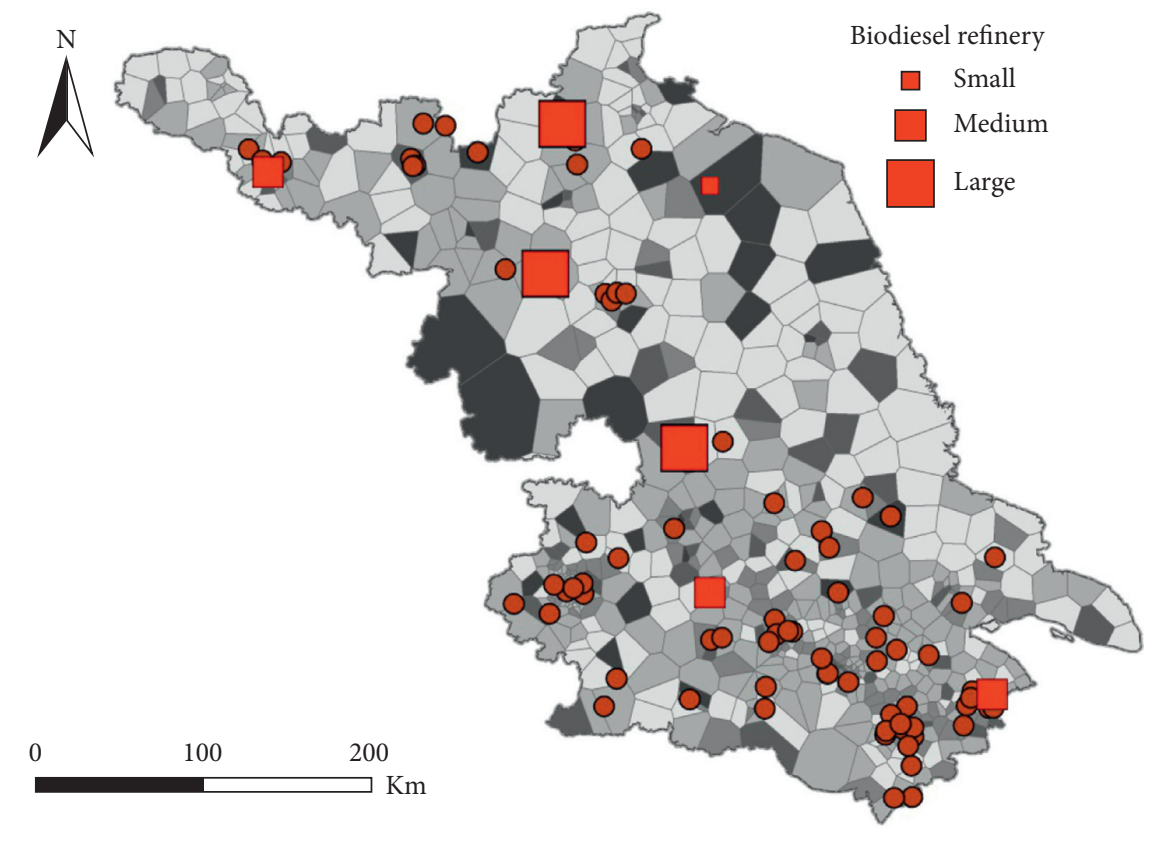

Kitchen waste supply
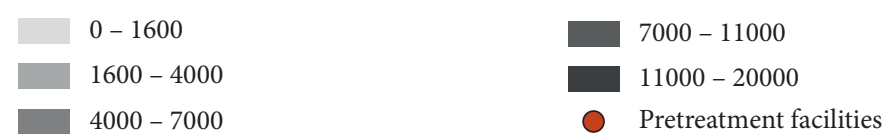

Figure 11: Results of biodiesel refineries and pretreatment facilities location.

million yuan, the social cost of running the biodiesel supply chain increased from about 165,000 tons of unused kitchen waste to about 185,000 tons. The trend of the Pareto curve reveals a tradeoff between economic and social effects. In particular, by comparing the two solutions with the red circle (phase 6 scale) in Figure 9, a well-chosen solution can be identified. Enterprises only do a small-scale expansion based on the lowest-cost solution, which makes a slight increase in economic cost and can significantly reduce the chaotic utilization of kitchen waste.

Then, consider the tradeoff between economic and environmental performance. According to the Pareto curve in Figure 10, with the expansion of the quantity and size of enterprise, the annual total cost increased from RMB283 million yuan to RMB289 million yuan, and the total carbon emissions increased from $147300 \mathrm{CO}_{2}$ eqv to 149700 $\mathrm{CO}_{2}$ eqv. This is the same with other industries. When an enterprise's production capacity and its scale increases, due to production, transportation, and other reasons, more carbon emissions are bound to be caused. The trend of the Pareto curve reveals a tradeoff between economic and environmental effects. In particular, by putting the two solutions with the red circle in the figure (phase 6 scale), we can see, compared with the lowest-cost solution, the early stage of the small-scale expansion will increase a lot of carbon emission. This is not conducive to the development of the industry, but the scale expansion of the later stage can significantly reduce the carbon emissions increasing amplitude and the trend of the Pareto curve reveals the tradeoff between economy and environment objectives. Considering the economic, social, and environmental objectives comprehensively, the three-dimensional Pareto surface was obtained by solving the optimization problem, and the reasonable development scale and site selection of facilities were further calculated. Based on the three objectives, when the biodiesel enterprises reach the sixth cycle scale, the biodiesel operators will reach the optimal state, which is the optimal scale for enterprise expansion.

4.4.2. Analysis of Site Selection Results under the Optimal Scale. From Figure 11, we can see there are many pretreatment facilities in the south and central parts of the province, which mainly promote the transfer of biomass to the factories in the north by collecting the kitchen waste in the south of Jiangsu Province with a relatively large supply. In this case, a total of 7 biodiesel refineries were selected, including Taicang City, Xiangshui County, Donghai County, Gaoyou City, Danyang City, Siyang County, and Tongshan County. All three large-scale biodiesel refineries are located in the northern part of Jiangsu Province. The optimal location for these biodiesel refineries is the county where the production capacity and conversion technologies and biodiesel refineries are the lowest-cost solution. They are relatively close to the blending facilities or demand points. In addition, it can be seen from the figure that although the construction cost of biodiesel refineries in central and southern Jiangsu Province is relatively high, there are still 
two medium-sized biodiesel refineries open in central and southeast Jiangsu Province due to the demand in these regions and the large supply of kitchen waste.

Pretreatment facilities are at the province of the three cities in the south of Jiangsu and Nanjing area which has more population. These cities produce more kitchen waste, and having pretreatment facility location in these cities can reduce transport costs. However, biodiesel refineries are located in areas with lower construction costs, which are relatively far from the demand point. The reason is that biodiesel has a higher density than the biomass materials, and the transportation costs are lower.

\section{Conclusions}

This paper presents a multiobjective biodiesel supply chain design model to optimize strategic decisions related to the biodiesel supply chain. In the construction of the model, the sustainable goals of economy, environment, and society are considered comprehensively. In the model solution, a heuristic algorithm based on Pareto optimality NSGAII is proposed to solve large-scale computational problems in supply chain, and it is applied to the case study of Jiangsu Province. The actual data were extracted by using the Baidu map, and the $K$-means clustering was used to preprocess the data. The objective value results show that the heuristic algorithm NSGAII based on Pareto optimality is suitable for large-scale biodiesel supply chain optimization research. With the expansion of biodiesel enterprises, the economic cost increases, the social target value (the amount of unused kitchen waste) is reduced, while the environmental target value (the cost of carbon emission) is increased. The design results of the supply chain network show that the pretreatment facilities are located in the places with large population and large supply of urban kitchen waste, so as to reduce the transportation cost of kitchen waste. Since biodiesel has a higher transport density than kitchen waste, biodiesel refineries are typically located in areas far from biodiesel demand and where construction costs are low. The paper has a reference for the study of biofuel supply chain in Jiangsu Province and the development of this industry in the future. Finally, although this study has comprehensively solved the biodiesel in different stages of the supply chain modeling and optimization, still some related works need further investigation, including the government's subsidy policy, different production technologies, design and operation of facilities of different priorities, and so on, which will become a biofuel supply chain research a development direction in the future.

\section{Data Availability}

The data used to support the findings of this study are available from the corresponding author upon request.

\section{Conflicts of Interest}

The authors declare that there are no conflicts of interest.

\section{Authors' Contributions}

Nana Geng and Yixiang Sun conceptualized the study and wrote the original draft. Nana Geng prepared methodology, analyzed using software, did formal analysis, investigated the study, and reviewed and edited the manuscript. Yixiang Sun was responsible for data curation.

\section{Acknowledgments}

This work was supported by the Nanjing University of Posts and Telecommunications research start-up fund (NY219168), Nature Foundation Incubation Fund of Nanjing University of Posts and Telecommunications (NY220214), and Project of Philosophy and Social Science Research in Colleges and Universities in Jiangsu Province (TJZ220011).

\section{References}

[1] E. Commission, Preparatory Study on Food Waste across EU27, European Commission, Brussels, Belgium, 2010.

[2] Report of Prospects and Investment Strategy Planning Analysis on China Food Waste Treatment Industry: 2017-2022.

[3] R. Chen, J. Jiang, R. Huang et al., "Review on recovery and reuse of waste oil," Innovation and Application of Science and Technology, vol. 9, no. 211, pp. 7-9, 2017.

[4] F. Zhou, Y. Xu, C. Tang et al., "Review on the development of food waste management policy in China," Low-carbon Econo, vol. 9, no. 2, p. 10, 2020.

[5] M. Eskandarpour, P. Dejax, J. Miemczyk, and O. Péton, "Sustainable supply chain network design: an optimizationoriented review," Omega, vol. 54, pp. 11-32, 2015.

[6] S. V. Mohan, G. Nikhil, P. Chiranjeevi et al., "Waste biorefinery models towards sustainable circular bioeconomy: critical review and future perspectives," Bioresource Technology, vol. 215, pp. 2-12, 2016.

[7] Y. Ge, L. Li, and L. Yun, "Modeling and economic optimization of cellulosic biofuel supply chain considering multiple conversion pathways," Applied Energy, vol. 281, 2021.

[8] H. Soleimaniankhezerlou, B. Vahdani, and M. Yazdani, "Designing a resilient and reliable biomass-to-biofuel supply chain under risk pooling and congestion effects and fleet management," Journal of Cleaner Production, vol. 281, Article ID 125101, 2020.

[9] G. Baudry, "How the cap limit for food-crop-based biofuels may affect France's stakeholders by 2030? a range-based multi-actor multi-criteria analysis," Transportation Research Part D: Transport and Environment, vol. 63, pp. 291-308, 2018.

[10] E. Gao, T. Sowlati, and S. Akhtari, "Profit allocation in collaborative bioenergy and biofuel supply chains," Energy, vol. 188, no. 1, pp. 116013.1-116013.13, 2019.

[11] G. Gosálbe, B. L. Montastruc, A. Stéphane Negny et al., "Optimal design and planning of biomass-to-biofuel supply chain considering economic dimension under strategic and tactical levels: a case study in Ethiopia," Computer Aided Chemical Engineering, vol. 48, pp. 1111-1116, 2020.

[12] E. Markel, C. Sims, and B. C. English, "Policy uncertainty and the optimal investment decisions of second-generation biofuel producers," Energy Economics, vol. 76, 2018.

[13] M. R. Anuar and A. Z. Abdullah, "Challenges in biodiesel industry with regards to feedstock, environmental, social and 
sustainability issues: a critical review," Renewable and Sustainable Energy Reviews, vol. 58, pp. 208-223, 2016.

[14] B. D. Solomon, "Biofuels and sustainability," Annals of the New York Academy of Sciences, vol. 1185, no. 1, pp. 119-134, 2010.

[15] R. A. Efroymson, H. I. Jager, S. Mandal et al., "Better management practices for environmentally sustainable production of microalgae and algal biofuels," Journal of Cleaner Production, vol. 289, pp. 125-150, 2021.

[16] F. Javed, M. Aslam, N. Rashid et al., "Microalgae-based biofuels, resource recovery and wastewater treatment: a pathway towards sustainable biorefinery," Fuel, vol. 255, pp. 115826.1-115826.15, 2019.

[17] W. Ramakrishna, P. Rathore, R. Kumari et al., "Brown gold of marginal soil: plant growth promoting bacteria to overcome plant abiotic stress for agriculture, biofuels and carbon sequestration," Science of the Total Environment, vol. 711, pp. 135062, 2020.

[18] G. Chiriboga, Andrés De La Rosa, C. Molina et al., "Energy return on investment (EROI) and life cycle analysis (LCA) of biofuels in Ecuador," Elsevier Public Health Emergency Collection, vol. 6, no. 6, 2020.

[19] A. Kumar, C. Guria, and A. K. Pathak, "Optimal cultivation towards enhanced algae-biomass and lipid production using Dunaliella tertiolecta for biofuel application and potential $\mathrm{CO} 2$ bio-fixation: effect of nitrogen deficient fertilizer, light intensity, salinity and carbon supply strategy," Energy, vol. 148, pp. 1069-1086, 2018.

[20] F. You, L. Tao, D. J. Graziano, and S. W. Snyder, "Optimal design of sustainable cellulosic biofuel supply chains: multiobjective optimization coupled with life cycle assessment and input-output analysis," AIChE Journal, vol. 58, no. 4, pp. 1157-1180, 2012.

[21] L. F. Lira-Barragán, J. M. Ponce-Ortega, M. Serna-González, and M. M. El-Halwagi, "Synthesis of integrated absorption refrigeration systems involving economic and environmental objectives and quantifying social benefits," Applied Thermal Engineering, vol. 52, no. 2, pp. 402-419, 2013.

[22] H. S. Bamufleh, J. M. Ponce-Ortega, and M. M. El-Halwagi, "Multi-objective optimization of process cogeneration systems with economic, environmental, and social tradeoffs," Clean Technologies and Environmental Policy, vol. 15, no. 1, pp. 185-197, 2013.

[23] A. Chaabane, A. Ramudhin, and M. Paquet, "Design of sustainable supply chains under the emission trading scheme," International Journal of Production Economics, vol. 135, no. 1, pp. 37-49, 2012.

[24] O. Akgul, N. Shah, and L. G. Papageorgiou, "An optimisation framework for a hybrid first/second generation bioethanol supply chain," Computers \& Chemical Engineering, vol. 42, pp. 101-114, 2012.

[25] J. Q. Neto, J. M. Bloemhof-Ruwaard, J. A. Van Nunen et al., Designing and Evaluating Sustainable Logistics Networks, University of Bath, Bath, UK, 2006.

[26] G. Guillén-Gosálbez, F. D. Mele, and I. E. Grossmann, "A bicriterion optimization approach for the design and planning of hydrogen supply chains for vehicle use," AIChE Journal, vol. 56, no. 3, pp. 650-667, 2010.

[27] A. Hugo, P. Rutter, S. Pistikopoulos, A. Amorelli, and G. Zoia, "Hydrogen infrastructure strategic planning using multiobjective optimization," International Journal of Hydrogen Energy, vol. 30, no. 15, pp. 1523-1534, 2005.

[28] K. Govindan, R. Khodaverdi, and A. Jafarian, "A fuzzy multi criteria approach for measuring sustainability performance of a supplier based on triple bottom line approach," Journal of Cleaner Production, vol. 47, pp. 345-354, 2013.

[29] E. Erkut, A. Karagiannidis, G. Perkoulidis, and S. A. Tjandra, "A multicriteria facility location model for municipal solid waste management in North Greece," European Journal of Operational Research, vol. 187, no. 3, pp. 1402-1421, 2008.

[30] M. Zhang, B. Wiegmans, and L. Tavasszy, "Optimization of multimodal networks including environmental costs: a model and findings for transport policy," Computers in Industry, vol. 64, no. 2, pp. 136-145, 2013.

[31] D. Yue, M. A. Kim, and F. You, "Design of sustainable product systems and supply chains with life cycle optimization based on functional unit: general modeling framework, mixed-integer nonlinear programming algorithms and case study on hydrocarbon biofuels," ACS Sustainable Chemistry \& Engineering, vol. 1, no. 8, pp. 1003-1014, 2013.

[32] D. Yue, M. Slivinsky, J. Sumpter, and F. You, "Sustainable design and operation of cellulosic bioelectricity supply chain networks with life cycle economic, environmental, and social optimization," Industrial \& Engineering Chemistry Research, vol. 53, no. 10, pp. 4008-4029, 2014.

[33] C. Pozo, R. Ruíz-Femenia, J. Caballero, G. Guillén-Gosálbez, and L. Jiménez, "On the use of Principal Component Analysis for reducing the number of environmental objectives in multi-objective optimization: application to the design of chemical supply chains," Chemical Engineering Science, vol. 69, no. 1, pp. 146-158, 2012.

[34] M. Pérez-Fortes, J. M. Laínez-Aguirre, P. Arranz-Piera, E. Velo, and L. Puigjaner, "Design of regional and sustainable bio-based networks for electricity generation using a multiobjective MILP approach,” Energy, vol. 44, no. 1, pp. 79-95, 2012.

[35] T. Xifeng, Z. Ji, and X. Peng, "A multi-objective optimization model for sustainable logistics facility location," Transportation Research Part D: Transport and Environment, vol. 22, pp. 45-48, 2013.

[36] G. Tuzkaya, B. Gülsün, and Ş. Önsel, “A methodology for the strategic design of reverse logistics networks and its application in the Turkish white goods industry," International Journal of Production Research, vol. 49, no. 15, pp. 4543-4571, 2011.

[37] A. Messac, A. Ismail-Yahaya, and C. A. Mattson, "The normalized normal constraint method for generating the Pareto frontier," Structural and Multidisciplinary Optimization, vol. 25, no. 2, pp. 86-98, 2003.

[38] C. Guo, X. Liu, M. Jin, and Z. Lv, "The research on optimization of auto supply chain network robust model under macroeconomic fluctuations," Chaos, Solitons \& Fractals, vol. 89, pp. 105-114, 2016.

[39] R. Li, S. Wu, Z. Song et al., "The impact of restaurant's type on their kitchen waste production," Environmental Engineering, vol. 34, pp. 762-764, 2016.

[40] Y. Zhang, Y. Jiang, M. Zhong et al., "Robust optimization on regional WCO-for-Biodiesel supply chain under supply and demand uncertainties," Scientific Programming, vol. 2016, Article ID 1087845, 15 pages, 2016.

[41] L. Tan, "Research status and application prospect of biodiesel from waste cooking oil," Chemical Production and Technology, vol. 14, no. 1, pp. 30-33, 2007.

[42] Y. Qi, Z. Wang, and Y. Li, "Cost analysis of food waste collection and transportation in Shanghai," Environmental Sanitation Engineering, vol. 16, no. 3, pp. 47-49, 2008.

[43] Q. Lu, Q. Zhu, and Z. He, Production Technology and Cost Analysis of Biodiesel at Home and Abroad, 2011. 
[44] Z. Liu, T. Qiu, and B. Chen, "A study of the LCA based biofuel supply chain multi-objective optimization model with multiconversion paths in China," Applied Energy, vol. 126, pp. 221-234, 2014.

[45] H. Chen, J. Liu, H. Zhong et al., "Carbon emission reduction potential analysis of different treatment modes of kitchen waste," Chinese Environmental Science, vol. 33, no. 11, pp. 2102-2106, 2013.

[46] T. R. P. Ramos, M. I. Gomes, and A. P. Barbosa-Póvoa, "Planning waste cooking oil collection systems," Waste Management, vol. 33, no. 8, pp. 1691-1703, 2013. 